\title{
Research on Zero Value Detection Technology of Porcelain Insulator
}

\author{
Mao Xiaopo ${ }^{1 *}$, Zhou Xueming ${ }^{1}$, Zhang Yaodong ${ }^{1}$, Li Zijian ${ }^{1}$, Huang Zeqi ${ }^{1}$, Feng Zhiqiang ${ }^{1}$, Ren Xiang ${ }^{1}$, Fu Jianjin ${ }^{1}$, \\ Huang Junjie ${ }^{1}$, Shi Tianru ${ }^{1}$ \\ ${ }^{1}$ Electric Power Research Institute, State Grid Hubei Electric Power Corporation, Wuhan, Hubei, 430077, China
}

\begin{abstract}
High-voltage insulators are one of the devices widely used in power systems, and their pros and cons are directly related to the safe and stable operation of the power system. The large-tonnage UHV insulator $\mathrm{AC}$ withstand voltage detection method is restricted by conditions at the engineering site, and the detection efficiency is low and difficult to implement. The research on the method of detecting UHV zerovalue insulators using high-voltage pulses and the development of portable detection devices are of great significance. This article has completed the portable insulator detection device using a miniaturized highvoltage pulse test power supply. The developed portable UHV zero-value insulator detection device can effectively judge zero-value, low-value and high-value UHV insulators, and adapt to large quantities of UHV insulators. Requirements for efficient testing.
\end{abstract}

\section{Introduction}

High-voltage insulators are one of the widely used equipment in power systems, and their pros and cons are directly related to the safety and stable operation of the power system ${ }^{[1]}$. Insulation resistance is an important parameter that characterizes the quality of insulators. Good insulation resistance is an important prerequisite to ensure its normal operation. In recent years, the zero value problem of UHV porcelain insulators has become more frequent in new operations and grid-connected operations, which has given rise to cross-regional power grids. Operational safety brings hidden dangers ${ }^{[2]}$. According to the $" 1000 \mathrm{kV}$ system electrical installation engineering equipment handover test standard" (GB/T 50832-2013), the suspension insulator handover test should meet two requirements: a $5000 \mathrm{~V}$ megohmmeter should be used to measure the insulation resistance of each suspension insulator before installation. It should not be lower than $500 \mathrm{M} \Omega$; AC withstand voltage test should be carried out, and the test voltage value should be $60 \mathrm{kV}$. Detecting the insulation performance of the insulator before installation or when necessary, and determining that it meets the specified use requirements is of great significance to the safe operation of the power grid ${ }^{[3]}$.

At present, the most important method for detecting the zero value of UHV line insulators is the use of highvoltage megohmmeters, with output voltages of $2500 \mathrm{~V}$ and $5000 \mathrm{~V}$. However, operating experience and test data show that the insulation resistance of large-tonnage UHV insulators is due to The test voltage of the traditional high- voltage megohmmeter is too low to effectively test lowzero insulators ${ }^{[4]}$. The on-site $\mathrm{AC}$ withstand voltage test power supply is not easy to obtain, and the $60 \mathrm{kV} \mathrm{AC}$ withstand voltage test equipment is bulky and difficult to carry ${ }^{[5]}$. In order to realize the rapid and accurate detection of large-tonnage zero-value or low-value high-voltage insulators on site, it is urgent to carry out research on the zero-value test method of large-tonnage porcelain insulators for UHV transmission lines and develop portable and effective test devices.

\section{Test research on zero-value insulator detection method}

At present, the technical methods for zero value detection of on-site insulators are limited, and there are certain misjudgments, resulting in low accuracy of the insulation resistance meter for detecting low zero value insulators. $\mathrm{AC}$ withstand voltage test is carried out in accordance with the regulations, and it is not easy to obtain the test in the field. The power supply and the withstand voltage device are cumbersome and difficult to transport. Consider using pulsed high voltage to test the insulation performance of large tonnage insulators. The pulse high-voltage power supply is small in size and can be powered by a battery, which can effectively solve the problem of heavy and difficult-to-handle AC withstand voltage test equipment.

Use a $50 \mathrm{kV}$ AC test transformer to boost the voltage, perform a withstand voltage test at $10 \mathrm{kV}, 20 \mathrm{kV}, 30 \mathrm{kV}$, $40 \mathrm{kV}$, and $50 \mathrm{kV}$, and record whether it passes the withstand voltage test. The test results are shown in Table.1. 
Tab.1 AC withstand voltage test results of UHV zero-value insulators

\begin{tabular}{|c|c|c|c|c|c|c|}
\hline \multirow{2}{*}{$\begin{array}{c}\text { Test voltage } \\
(\mathrm{kV})\end{array}$} & \multicolumn{2}{|c|}{$1 \mathrm{~s}(\mathrm{G} \Omega)$} & \multicolumn{2}{c|}{$15 \mathrm{~s}(\mathrm{G} \Omega)$} & \multicolumn{2}{c|}{$60 \mathrm{~s}(\mathrm{G} \Omega)$} \\
\cline { 2 - 7 } & Low value & High value & Low value & High value & Low value & High value \\
\hline 10 & $\begin{array}{c}\text { No } \\
\text { breakdown }\end{array}$ & $\begin{array}{c}\text { No } \\
\text { breakdown }\end{array}$ & $\begin{array}{c}\text { No } \\
\text { breakdown }\end{array}$ & $\begin{array}{c}\text { No } \\
\text { breakdown }\end{array}$ & $\begin{array}{c}\text { No } \\
\text { breakdown }\end{array}$ & $\begin{array}{c}\text { No } \\
\text { breakdown }\end{array}$ \\
\hline 20 & $\begin{array}{c}\text { No } \\
\text { breakdown }\end{array}$ & $\begin{array}{c}\text { No } \\
\text { breakdown }\end{array}$ & $\begin{array}{c}\text { No } \\
\text { breakdown }\end{array}$ & $\begin{array}{c}\text { No } \\
\text { breakdown }\end{array}$ & $\begin{array}{c}\text { No } \\
\text { breakdown }\end{array}$ & $\begin{array}{c}\text { No } \\
\text { breakdown }\end{array}$ \\
\hline 30 & $\begin{array}{c}\text { No } \\
\text { breakdown }\end{array}$ & $\begin{array}{c}\text { No } \\
\text { breakdown }\end{array}$ & $\begin{array}{c}\text { No } \\
\text { breakdown }\end{array}$ & $\begin{array}{c}\text { No } \\
\text { breakdown }\end{array}$ & $\begin{array}{c}\text { No } \\
\text { breakdown }\end{array}$ & $\begin{array}{c}\text { No } \\
\text { breakdown }\end{array}$ \\
\hline 40 & $\begin{array}{c}\text { No } \\
\text { breakdown }\end{array}$ & $\begin{array}{c}\text { No } \\
\text { breakdown }\end{array}$ & $\begin{array}{c}\text { No } \\
\text { breakdown }\end{array}$ & $\begin{array}{c}\text { No } \\
\text { breakdown } \\
\text { breakdown }\end{array}$ & $\begin{array}{c}\text { No } \\
\text { breakdown }\end{array}$ \\
\hline 44 & Breakdown & Breakdown & $\begin{array}{c}\text { No } \\
\text { breakdown }\end{array}$ & Breakdown & $\begin{array}{c}\text { No } \\
\text { breakdown }\end{array}$ \\
\hline
\end{tabular}

Comparing the data in the table, the high-value and low-value UHV insulators measured by the insulation resistance meter under the test voltages of $2500 \mathrm{~V}$ and $5000 \mathrm{~V}$, the insulation resistance is far greater than $500 \mathrm{M}$, which cannot accurately reflect the insulation characteristics of the UHV insulator; the pulse high voltage method is in the voltage amplitude Under the condition of $10 \mathrm{kV}$, the measurement result is far greater than $500 \mathrm{M}$, and the detection result is not accurate. Under the condition of pulse voltage amplitude of $50 \mathrm{kV}$, the measurement result of low-value insulator is less than $250 \mathrm{M}$, and high-value insulator is greater than $1 \mathrm{G}$, which can accurately detect low-value UHV insulators. When the $\mathrm{AC}$ resistance voltage test voltage is lower than $40 \mathrm{kV}$, the low-value insulator will not be broken down, and the defective insulator cannot be effectively detected. When the test voltage is $44 \mathrm{kV}$, the low-value insulator breaks down, and the high-value insulator passes the withstand voltage test, effectively detecting the defective insulator.

The test voltage of the lower AC withstand voltage test and the pulse method test voltage have low accuracy in detecting defective insulators. Under $10 \mathrm{kV}$ pulse high voltage and $40 \mathrm{kV}$ AC high voltage, the defects of the insulator are not broken down, indicating that the amplitude of the test voltage is required. Only when a certain level is reached can the defects of UHV low-value insulators be effectively stimulated and accurate and reliable detection can be realized.

Under different high-voltage pulse widths, the measured UHV insulator resistance value has a certain change. It is necessary to test and analyze the relationship between the high-voltage pulse width and the insulation resistance test result, and select the appropriate test pulse width to achieve the purpose of accurate detection. The test results show that testing UHV insulators with pulse high voltage with appropriate amplitude and width can effectively detect low (zero) value insulators, instead of
AC withstand voltage test, and solve the problem of inaccessible power supply and transportation inconvenience in the field of $\mathrm{AC}$ withstand voltage test. The problem.

\section{Design of portable zero-value insulator detection device}

\subsection{General requirements}

(1) Device functional requirements

Output high-voltage pulses with adjustable width and amplitude to measure the resistance of UHV insulators; to ensure test safety, Bluetooth wireless communication is used to control the working status of the device, and highvoltage pulse output and signal acquisition are started; test data is transmitted to the handheld through Bluetooth communication Type control equipment for data display and analysis and judgment.

(2) Requirements for key technical indicators of the device

Maximum output voltage: $\mathrm{DC} 60 \mathrm{kV}$; high voltage pulse width: $50 \mathrm{~ms}, 100 \mathrm{~ms}, 200 \mathrm{~ms}$, can be set; voltage measurement resolution: $0.1 \mathrm{kV}$; voltage measurement accuracy: $\pm(5 \%+1$ readings $)$; current measurement resolution: $0.05 \mathrm{uA}$; Current measurement accuracy: $\pm(5 \%+1$ readings $)$; high-value insulator test times: 5000 times; power supply: DC24V.

\subsection{Overall structure of the device}

According to the requirements of the zero-value insulator high-voltage pulse method, the prototype of the test device is designed. The overall structure is shown in Fig.1. 


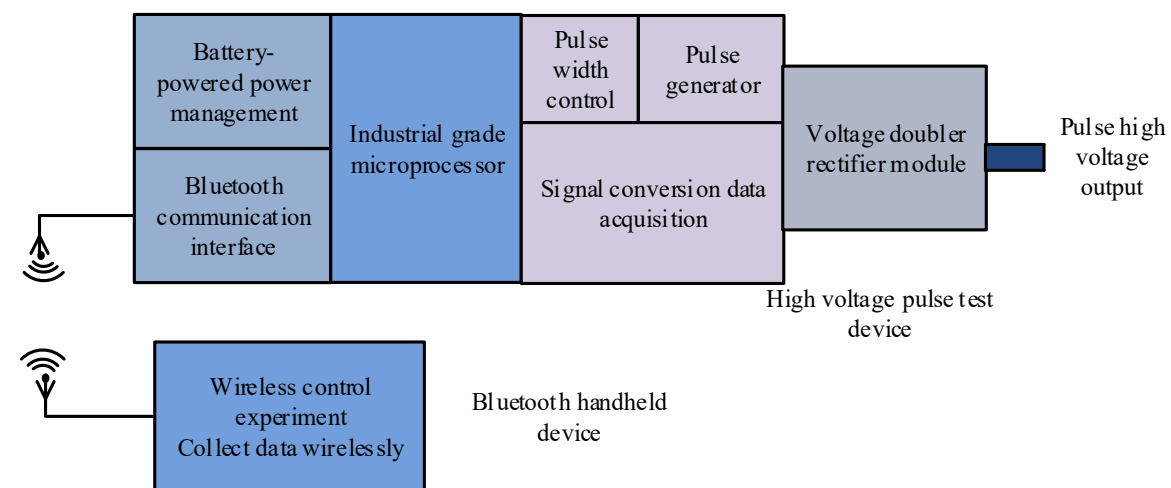

Fig.1 The frame of the high-voltage pulse zero-value insulator detection device

The high-voltage pulse zero-value insulator detection device is divided into two parts, one is a Bluetooth handheld device, and the other is a high-voltage pulse test device. The Bluetooth handheld device completes functions such as wireless setting of high-voltage pulse width, wireless start-up and control of high-voltage pulse output, wireless collection of measurement data, and measurement result display and analysis. The high-voltage pulse test device uses industrial-grade microprocessor as the core, including power supply battery and power management module, Bluetooth wireless communication interface module, signal pulse width control and pulse generator module, signal conversion and acquisition module, Bluetooth handheld device according to the received high voltage Set the pulse width, complete highvoltage pulse output and signal conversion and acquisition, and upload the results.

\subsection{Part of the circuit module}

The first-stage boost circuit uses push-pull to boost the DC low voltage to the required first-stage DC bus voltage. In the first-stage boost circuit, through the feedback and high-voltage output program-controlled shifting part, it is used to adjust the first-stage DC bus voltage output. The second-stage boost part uses a half-bridge topology to invert the DC bus voltage into an intermediate frequency square wave voltage. The intermediate frequency voltage is boosted into an intermediate frequency high voltage through a high voltage package, and it becomes a DC high voltage through a 6 times voltage rectification. The voltage doubler rectifier circuit is shown in Fig.2.

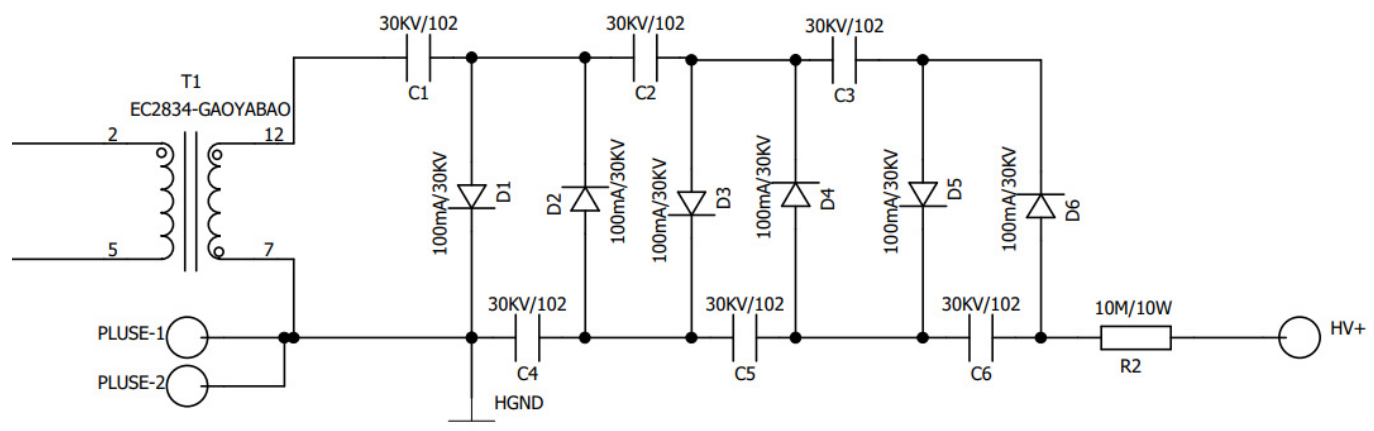

Fig.2 Voltage doubler rectifier circuit

Adopt STM32F429 processor as the control center. Control of high-voltage pulse power supply, range switching, and output pulse time. The processor and the
Bluetooth module exchange data, receive signals from the handheld terminal, and send the collected data. The bluetooth circuit is shown as in Fig.3.

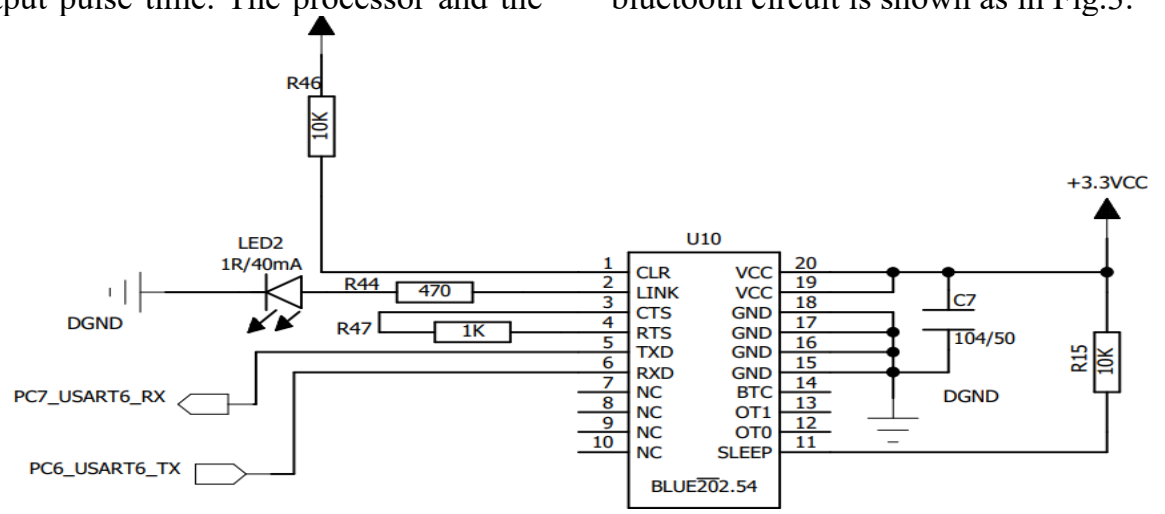

Fig.3 Bluetooth circuit 


\subsection{Signal sampling method and result calculation method}

Considering the convenience and safety of on-site use, the high-voltage pulse detection device adopts battery power supply. The whole device is suspended relative to the earth, and only the output high-voltage head and output highvoltage tail are drawn, which is convenient for direct detection of the insulator out of the box. The pulse of signal sampling is high-voltage inside the device. The pulse voltage is sampled by resistor divider, and the resistance arm is set between the output high voltage head and the pulse high voltage tail. The pulse current is sampled by resistance, and the sampling resistance is set between the output high voltage tail and the pulse high voltage tail. Fig.4 shows the calculation and analysis of the collected signal.

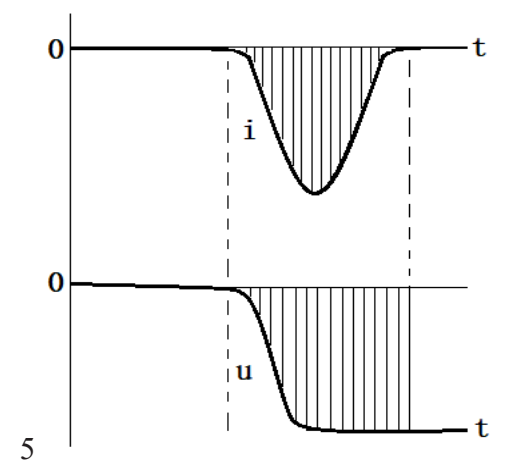

Fig.4 Schematic diagram of signal calculation and analysis

According to the collected current and the continuous pulse width $\mathrm{T}$ of the current signal $\mathrm{i}$, the effective value of the signal is calculated.

$$
\begin{gathered}
I=\frac{\sum i \times \Delta t}{T} \\
U=\frac{\sum u \times \Delta t}{T}
\end{gathered}
$$

Suppose the current V/I conversion coefficient and the voltage divider ratio coefficient are and respectively, then the resistance of the insulator under pulsed high voltage can be calculated.

$$
R=\frac{U \times k_{U}}{I \times k_{I}}
$$

\subsection{Device body}

The appearance of the prototype of the detection device is shown in Fig.5. The prototype of the testing device weighs about $2.4 \mathrm{~kg}$, has a diameter of $35 \mathrm{~mm}$, and a height of $3800 \mathrm{~mm}$. It is operated by a handheld tablet.

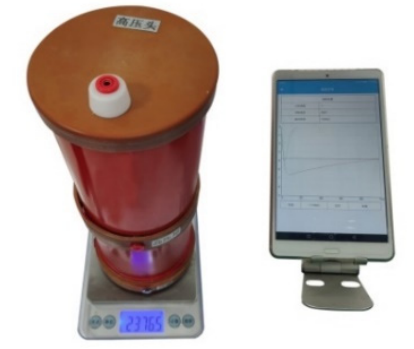

Fig.5 Device body

\section{Conclusion}

Insulation resistance meters cannot effectively detect UHV low-value and zero-value insulators. The AC withstand voltage test method for large-tonnage UHV insulators is limited by conditions at the project site, and the detection efficiency is low and difficult to implement. The high-voltage pulse detection of UHV low-value or zero-value insulators has a high accuracy rate. The research on the method of detecting UHV zero-value insulators using high-voltage pulses and the development of portable detection devices are of great significance.

(1) The completed portable insulator detection device uses a miniaturized high-voltage pulse test power supply, and the impact of the test voltage amplitude and width on the measurement results is studied, and the output pulse voltage is determined to be greater than $60 \mathrm{kV}$ and the pulse width is $100 \mathrm{~ms}$. The quality of the detection device is not more than $3 \mathrm{kG}$, and the equipment is small and portable. The voltage measurement deviation is less than $\pm 5 \%$; the insulation resistance test range is $0-5000 \mathrm{M}$, and the measurement deviation is less than $\pm 10 \%$; a single charge can be used continuously for 5000 times.

(2) By comparing the results of insulation resistance meter and $\mathrm{AC}$ withstand voltage test, the developed portable UHV zero-value insulator detection device can effectively judge zero-value, low-value and high-value UHV insulators. The detection speed is fast, and the detection time of single-piece insulators is $10 \mathrm{~s}$, which can meet the requirements of accurate and efficient detection of large quantities of UHV insulators on site.

\section{References}

1. Wang Wankun, Zhou Xueming, Hu Danhui, et al. Research on Causes of Zero Value of $220 \mathrm{kV}$ Suspension Porcelain Insulator [J]. Hubei Electric Power. 2019, 43(05): 27-32.

2. Zhou Xueming, Huang Jianglin, Hu Danhui, et al. Diagnosis method of deteriorated porcelain insulation string based on infrared detection [J]. Hubei Electric Power. 2020, 44(01): 73-79.

3. Lu Qi, Zhou Xueming, Zhang Bin, et al. Analysis and Countermeasures of Porcelain Insulator Explosion in High Voltage Transmission Line [J]. Hubei Electric Power. 2019, 43(06): 22-27.

4. YAO Jiangang,ZHANG Ye, LI Tangbing, etal.Analysis of High-voltage Ceramic Insulators Infrared Detection Blind Areas.High Voltage 
Engineering ,2017, 43(9):2903-2910.

5. JIANG Xiuceng. Research on the judgment method of low zero value insulator [J]. High Voltage Engineering, 1995, 21(3): 72-75. 